\title{
Knowledge Organization
}

\section{First Annual "Best Paper in KO Award" for Volume 40 (2013) ${ }^{\dagger}$}

\author{
Awarded jointly to: \\ Birger Hjørland, \\ for "Theories of knowledge organization-Theories of knowledge." \\ KO 40, no. 3: 169-81 \\ and \\ Jens-Erik Mai, \\ for "Ethics, values and morality in contemporary library classifications." \\ KO 40, no. 4: 242-53.
}

Birger Hjørland, for "Theories of knowledge organization-Theories of knowledge.” KO 40, no. 3: 169-81.

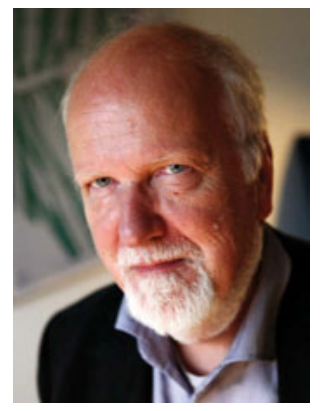

ABSTRACT: Any ontological theory commits us to accept and classify a number of phenomena in a more or less specific wayand vice versa: a classification tends to reveal the theoretical outlook of its creator. Objects and their descriptions and relations are not just "given," but determined by theories. Knowledge is fallible, and consensus is rare. By implication, knowledge organization has to consider different theories/views and their foundations. Bibliographical classifications depend on subject knowledge and on the same theories as corresponding scientific and scholarly classifications. Some classifications are based on logical distinctions, others on empirical examinations, and some on mappings of common ancestors or on establishing functional criteria. To evaluate a classification is to involve oneself in the research which has produced the given classification. Because research is always based more or less on specific epistemological ideals (e.g., empiricism, rationalism, historicism, or pragmatism), the evaluation of classification includes the evaluation of the epistemo- logical foundations of the research on which given classifications have been based. The field of knowledge organization itself is based on different approaches and traditions such as user-based and cognitive views, facetanalytical views, numeric taxonomic approaches, bibliometrics, and domain-analytic approaches. These approaches and traditions are again connected to epistemological views, which have to be considered. Only the domain-analytic view is fully committed to exploring knowledge organization in the light of subject knowledge and substantial scholarly theories.

Birger Hjørland holds an M.A. in psychology and Ph.D. in library and information science. He is professor in knowledge organization at the Royal School of Library and Information Science in Copenhagen since 2001 and at the University College in Borås 2000-2001. He was research librarian and coordinator of computer based information services at the Royal Library in Copenhagen 1978-1990, and taught information science at the Department of Mathematical and Applied Linguistics at the University of Copenhagen 1983-1986. He is chair of ISKO's Scientific Advisory Council and a member of the editorial boards of Knowledge Organization, Journal of the Association for Information Science and Technology and Journal of Documentation. 
Jens-Erik Mai, for "Ethics, values and morality in contemporary library classifications." KO 40, no. 4: 242-253.

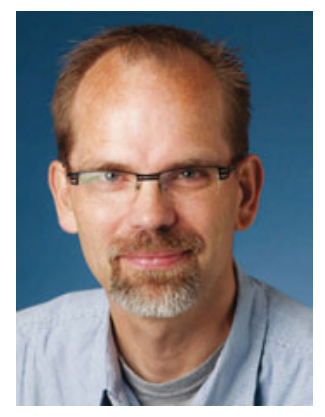

ABSTRACT: This paper explores the ethics of classification. The paper outlines recent conceptual moves in knowledge organization research and shows that contemporary classification theory is based on a pragmatic understanding of the world. It suggests that unjust statements and assumptions about the world challenge contemporary library classifications and that a proper response is needed. It outlines a framework for the development of ethical classifications based on MacIntyre's practice-based ethical theory. It provides a framework within which editors and managers of library classifications can make ethically sound decisions.

Jens-Erik Mai is professor at the University of Copenhagen, Royal School of Library and Information Science in Denmark. He was previously associate professor at the Faculty of Information, University of Toronto where he also served as Vice Dean and Acting Dean. Prior to that he was assistant professor at the Information School of the University of Washington where he co-directed the Center for Human-Information Interaction. He earned his Ph.D. in library and information science from the
University of Texas at Austin as a Fulbright Scholar and his master's and bachelor's degrees from the Royal School of Library and Information Science, Denmark.

He teaches classes in knowledge organization, information ethics, and knowledge media - and he writes papers about classification, the nature of information, trust and authority, and the design of controlled vocabularies.

Jens-Erik is interested in basic questions about the nature of information phenomena; he has explored these from a variety of conceptual points (e.g. semiotics, cognitive work analysis, late-modernity, philosophy of language, trust) often with a focus on issues and questions in the organization of information. He has contributed conceptual constructions as well as methodological and programmatic papers that have helped forward thinking about the organization of information.

Jens-Erik was a member of the ISKO Executive Board from 2002 to 2006, he has been a member of the program committee for the ISKO International Conference in 2000, 2002, 2004, 2006 and 2008, and he has been a member of editorial board for Knowledge Organization since 2006. JensErik serves on ASIS\&T Board of Directors (2012-2014), and he was the Conference Chair for iConference 2012 held in Toronto and is the Conference Chair for the 77th ASIS\&T Annual Meeting 2014 to be held in Seattle.

† Awards Committee for Volume 40 (2013): Jonathan Furner, chair; Jesus Gascon-Garcia, Jose Augusto Guimaraes, Maja Zumer, Ia McIlwaine 